\section{Time trends in eating disorder incidence}

\section{LAURA CURRIN, ULRIKE SCHMIDT, JANET TREASURE and HERSHEL JICK}

\section{Background During the years 1988 \\ 1993 the primary care incidence of anorexia nervosa in the UK remained stable, but the incidence of bulimia nervosa increased threefold.}

\section{Aims To determine whether the incidence of anorexia nervosa remained stable, and that of bulimia nervosa continued to increase, in the years 1994-2000.}

\section{Method The General Practice Research Database was screened for new cases of anorexia and bulimia nervosa between 1994 and 2000. Annual incidence rates were calculated for females aged 10-39 years and compared with rates from the previous 5 years.}

Results In 2000 primary care incidence rates were 4.7 and 6.6 per 100000 population for anorexia and bulimia nervosa, respectively. The incidence of anorexia nervosa remained remarkably consistent over the period studied.Overall there was an increase in the incidence of bulimia, but rates declined after a peak in 1996.

\section{Conclusions This study provides further evidence for the stability of anorexia nervosa incidence rates. Decreased symptom recognition and changes in service use might have contributed to observed changes in the incidence of bulimia nervosa.}

\section{Declaration of interest None.}

Trends in disease incidence are important for conceptualising disease aetiology and planning health services. Several studies have used meta-analysis to determine whether eating disorder incidence has changed over time, although these have largely focused on anorexia nervosa. Prior results indicate a small global increase in the incidence of anorexia nervosa throughout the 20th century (Keel \& Klump, 2003), with a stable European incidence since the 1970s (Hoek \& van Hoeken, 2003). Only three studies have specifically focused on trends in the incidence of bulimia nervosa, owing to its later recognition as a diagnostic category and the tendency to report prevalence rather than incidence. However, prior work found a threefold increase in the UK primary care incidence of bulimia nervosa between 1988 and 1993 (Turnbull et al, 1996). This leaves two important questions: has the incidence of anorexia nervosa remained stable, and is the incidence of bulimia nervosa continuing to rise as dramatically as previously reported?

\section{METHOD}

We analysed the annual incidence rates of eating disorders within a primary care setting, extending the work done by Turnbull et al (1996). The General Practice Research Database (GPRD; http:// www.gprd.com) was searched for newly recorded cases of anorexia and bulimia nervosa between 1994 and 2000 inclusive. This database covers approximately 280 general practitioners and over 3 million patients (about $5 \%$ of the total UK population). Although inner-London and smaller practices are slightly underrepresented, the patients are broadly representative of the UK population with respect to age and gender. Diagnostic information was recorded using a modified version of the Oxford Medical Information System (OXMIS) or Read classification system (depending on the year in question). The high quality of data recording has been previously validated (Walley \& Mantgani, 1997; Jick et al, 2003).

The GPRD was searched for first-time diagnoses of anorexia and bulimia nervosa made between 1 January 1994 and 31 December 2000. Annual incidence rates were calculated for women aged 10-39 years. This cohort represents the vast majority of registered cases, and was the group considered in the previous study (Turnbull et al, 1996). Incidence rates were calculated by dividing the number of eating disorder cases diagnosed annually by the total number of people in this age group registered with a general practitioner (GP) in that year. These annual incidence rates were then compared with figures collected using an identical method from the years 19881993 (Turnbull et al, 1996). In addition, incidence for the total population was calculated for the year 2000, and stratified by age group and gender.

During the period studied there have been changes to the formal diagnostic criteria for bulimia nervosa. However, the GPRD uses general practitioner rather than psychiatric diagnoses, minimising the effect of these changes. In addition, concurrent notes and referral letters for cases from the year of peak incidence were compared with those from the most recent year available to determine whether there had been changes in diagnostic habits.

\section{RESULTS}

Over the period studied, annual incidence rates for diagnosed anorexia nervosa remained stable for females aged 10-39 years (Fig. 1). The rate in 1988 was 18.5 per $100000(95 \%$ CI 10.2-26.9) and in the year 2000 the rate was 20.1 per 100000 (95\% CI 15.0-25.2), with minimal variation in the intervening years. In 2000 the age- and gender-adjusted incidence of anorexia nervosa diagnosed in primary care was 4.7 per 100000 population $(95 \% \mathrm{CI}$ 3.6-5.8). The incidence rate varied dramatically according to the age-gender group (Table 1). The incidence rate for females was 8.6 per 100000 (95\% CI 6.5-10.6) compared with 0.7 per 100000 (95\% CI 0.1-1.3) for males. This translated to a relative risk for females to males of 12:1. The highest incidence, 34.6 per 100000 population (95\% CI 22.0-47.1), was found in females aged 10-19 years. 


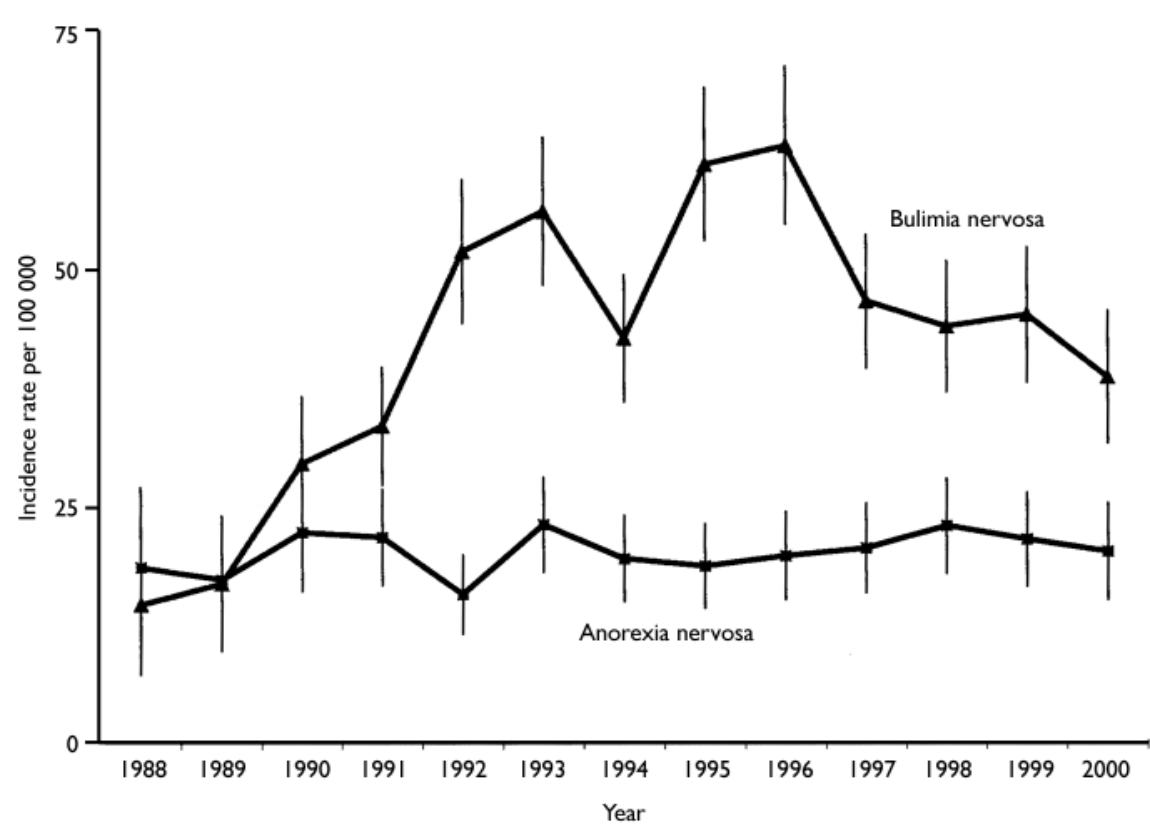

Fig. I Annual incidence of anorexia and bulimia nervosa in women aged 10-39 years from 1988 to 2000 (error bars represent $95 \% \mathrm{Cl}$ ).

The results for bulimia nervosa are very different. As demonstrated by Turnbull et al (1996), the early 1990s showed a marked increase in primary care incidence for women aged 10-39 years which continued until 1996. Although there was an overall increase in reported cases of bulimia nervosa from 1988-2000, the incidence rate has fallen by $38.9 \%$ since this peak (Fig. 1). In 2000 the age- and gender-adjusted incidence of bulimia nervosa in primary care was 6.6 per 100000 (95\% CI 5.3-7.9). The incidence rate for females was 12.4 per 100000 (9.9-14.9) compared with 0.7 per 100000 (95\% CI 0.1-1.3) for males. This represents a relative risk for females to males of approximately 18:1. The highest incidence, 35.8 per $100000(95 \%$ CI 23.0-48.6), was in females aged 10-19 years.

To control for the changing criteria applied to bulimia nervosa, diagnostic validity was analysed in a subgroup of cases randomly selected from the years 1996 $(n=26)$ and $2000(n=19)$. There are considerable difficulties associated with a retrospective validation of diagnoses owing to the limited information available. Cases were defined as 'probable bulimia nervosa' if all but one of the DSM-IV criteria (American Psychiatric Association, 1994) were mentioned in the case history. Seventeen of the cases $(37.3 \%)$ had insufficient information available to validate diagnoses. Of the remaining cases, a similar proportion of cases in 1996 and 2000 were either 'full' or 'probable' bulimia nervosa $(82.3 \%$ and $81.8 \%$, respectively). It is important to note that all of the remaining cases were considered to be eating disorder cases (either 'not otherwise specified' or anorexia nervosa).

\section{DISCUSSION}

The incidence rate of anorexia nervosa in primary care has remained extremely stable over the 12 years studied. In contrast, reported cases of bulimia nervosa increased

Table I Incidence of anorexia nervosa per 100000 population for the year 2000

\begin{tabular}{|c|c|c|c|c|c|c|c|c|c|}
\hline \multirow[t]{2}{*}{ Age (years) } & \multicolumn{3}{|c|}{ Females } & \multicolumn{3}{|c|}{ Males } & \multicolumn{3}{|c|}{ Total } \\
\hline & Cases $n$ & $\begin{array}{l}\text { Registered } \\
\text { population } n\end{array}$ & Incidence $(95 \% \mathrm{Cl})$ & Cases $n$ & $\begin{array}{l}\text { Registered } \\
\text { population } n\end{array}$ & Incidence $(95 \% \mathrm{Cl})$ & Cases $n$ & $\begin{array}{l}\text { Registered } \\
\text { population } n\end{array}$ & Incidence $(95 \% \mathrm{Cl})$ \\
\hline $0-9$ & 0 & 91168 & 0 & 0 & 95646 & 0 & 0 & 186814 & 0 \\
\hline $10-19$ & 29 & 83866 & $34.6(22.0-47.1)$ & 2 & 88092 & $2.3(0-5.4)$ & 31 & $17 \mid 958$ & $18.0(\mid 1.7-24.4)$ \\
\hline $20-39$ & 22 & 209761 & $10.5(6.1-14.9)$ & 1 & 209525 & $0.5(0-1.4)$ & 23 & 419286 & $5.5(3.2-7.7)$ \\
\hline $40+$ & 14 & 374150 & $3.7(1.8-5.7)$ & 2 & 342503 & $0.6(0-1.4)$ & 16 & 716653 & $2.2(1.1-3.3)$ \\
\hline Total & 65 & 758945 & $8.6(6.5-10.6)$ & 5 & 735766 & $0.7(0.1-1.3)$ & 70 & | 4947|| & $4.7(3.6-5.8)$ \\
\hline
\end{tabular}

Table 2 Incidence of bulimia nervosa per 100000 population for the year 2000

\begin{tabular}{|c|c|c|c|c|c|c|c|c|c|}
\hline \multirow[t]{2}{*}{ Age (years) } & \multicolumn{3}{|c|}{ Females } & \multicolumn{3}{|c|}{ Males } & \multicolumn{3}{|c|}{ Total } \\
\hline & Cases $n$ & $\begin{array}{l}\text { Registered } \\
\text { population } n\end{array}$ & Incidence $(95 \% \mathrm{Cl})$ & Cases $n$ & $\begin{array}{l}\text { Registered } \\
\text { population } n\end{array}$ & Incidence $(95 \% \mathrm{Cl})$ & Cases $n$ & $\begin{array}{l}\text { Registered } \\
\text { population } n\end{array}$ & Incidence $(95 \% \mathrm{Cl})$ \\
\hline $0-9$ & 0 & 91168 & 0 & 0 & 95646 & 0 & 0 & 186814 & 0 \\
\hline $10-19$ & 30 & 83866 & $35.8(23.0-48.6)$ & 3 & 88092 & $3.4(0-7.3)$ & 33 & $17 \mid 958$ & $19.2(12.6-25.7)$ \\
\hline $20-39$ & 60 & 209761 & $28.6(21.4-35.8)$ & 2 & 209525 & $1.0(0-2.3)$ & 62 & 419286 & I4.8 (II.I-18.5) \\
\hline $40+$ & 4 & 374150 & I.I $(0-2.1)$ & 0 & 342503 & 0 & 4 & 716653 & $0.6(0-1 . I)$ \\
\hline Total & 94 & 758945 & $12.4(9.9-14.9)$ & 5 & 735766 & $0.7(0.1-\mathrm{I} .3)$ & 99 & | 4947|| & $6.6(5.3-7.9)$ \\
\hline
\end{tabular}


during the same period. However, the peak in bulimia cases seen in 1996 was followed by a subsequent decline for the remainder of the study. This decline was almost entirely explained by the decrease in incidence rates for females aged 20-39 years. In 1993 the incidence rate for this group was 56.7 per 100000 (95\% CI 49.2-64.3) (Turnbull et al, 1996), but by 2000 it had fallen to 28.6 per 100000 (95\% CI 21.4-35.8). In contrast, the incidence of bulimia nervosa in women aged 10-19 years has remained relatively stable: 41.0 per 100000 in 1993 compared with 35.8 per 100000 in 2000 (Turnbull et al, 1996).

\section{CONTEXT OF FINDINGS}

The stability of anorexia nervosa incidence is consistent with reports from a review by Hoek \& van Hoeken (2003), and the ageand gender-adjusted incidence is comparable with that found in another primary-care study (Hoek et al, 1995). Our data suggest that the previous trend of increasing incidence of bulimia nervosa in primary care has not continued, and therefore the ageand gender-adjusted incidence reported here is lower than other comparable figures (Hoek et al, 1995; Soundy et al, 1995). This finding, that young women aged 10-19 years have the highest risk of both anorexia and bulimia nervosa, corresponds with other epidemiological evidence that eating disorders emerge in late adolescence (Soundy et al, 1995; Lucas et al, 1999; Lewinsohn et al, 2000).

A major strength of our study is the use of a nationally representative primary care database. Because of the structure of the UK health system most patients will pass through the care of a GP, even if later referred to specialist services. Additionally, $20 \%$ of patients with anorexia nervosa and $40 \%$ of patients with bulimia nervosa are treated exclusively in primary care (Turnbull et al, 1996). Moreover, time trends were assessed using the same method over the entire study period, rather than depending on meta-analysis. However, the use of a primary care database is itself a limitation, in that the reported figures represent clinically meaningful cases rather than those meeting DSM-IV criteria. This parallels the picture seen in other studies of clinical cases. Several specialist services consistently report that the most common diagnosis is 'eating disorders not otherwise specified', and these cases are no less severe

\section{CLINICAL IMPLICATIONS}

- The incidence of anorexia nervosa detected by general practitioners has remained stable for the years 1988-2000, whereas the incidence of bulimia was marked by a dramatic increase in the 1990s and now appears to be falling.

Special detection and treatment efforts should be aimed at young women aged $10-19$ years, as this is the age group with the highest risk of both anorexia and bulimia nervosa.

- General practitioners need more information about the presentation of eating disorder symptoms and the treatments available, to allow early and effective intervention.

\section{LIMITATIONS}

- Only those approaching their general practitioner for treatment could be detected; this study cannot estimate the number in the community who do not seek help for their condition.

- Incidence is calculated from general practitioners' clinical diagnoses rather than DSM-IV criteria.

It cannot yet be determined whether the decline in bulimia nervosa incidence during the last 4 years of our study represents a true decrease in disease incidence or is due to other changing circumstances.

LAURA CURRIN, BA, Section of Eating Disorders, Institute of Psychiatry and Mental Health Department, St George's Hospital Medical School, London; ULRIKE SCHMIDT, MD, MPhil, PhD, MRCPsych, Section of Eating Disorders, Institute of Psychiatry; JANET TREASURE, MD, PhD, FRCP, FRCPsych, Section of Eating Disorders, Institute of Psychiatry and Guy's, King's and St Thomas's Medical School, London, UK; HERSHEL JICK, MD, Boston University School of Medicine, Boston, Massachusetts, USA

Correspondence: Laura Currin, Section of Eating Disorders, Box 059, Institute of Psychiatry,

De Crespigny Park, London SE5 8AF, UK. Tel: +44 (0)20 7848 0367; fax: +44 (0)20 78480182 ; e-mail: I.currin@iop.kcl.ac.uk

(First received 23 June 2004, accepted 3 September 2004)

in presentation or illness duration than those meeting full diagnostic criteria (Millar, 1998; Ricca et al, 2001; Fairburn \& Harrison, 2003; Turner \& Bryant-Waugh, 2004). A second limitation is that only those identified by their GP are reported in this study; therefore, this study cannot estimate the true community incidence of these disorders. This limitation is shared by all epidemiological studies that use service registers.

\section{CHANGES IN BULIMIA NERVOSA}

There are several potential explanations of the peak in incidence of bulimia nervosa seen in the 1990s and its subsequent decline. It is possible that patients may now seek help from different sources. During the study period, the UK-based Eating Disorder Association (http://www. edauk.com) has experienced a dramatic increase in demand for its web-based messaging and e-mail service (S. Ringwood, Eating Disorder Association, personal communication, 2004). Perhaps patients are now turning to a range of different support services, rather than relying primarily on their GP. Another possible explanation relates to changes in professional or public attention to eating disorder symptoms. The earlier period of rising incidence of bulimia might have been the result of 
increased recognition and detection efforts given to a new and 'fashionable' diagnosis. In line with this theory, the decrease in identified cases mirrors a decline in eating disorder research publications. Between the years 1960 and 2000 the number of references about eating disorders in general - and bulimia in particular-grew proportionately much faster than the total number of Medline citations (Theander, 2002). However, during the 1990 s this rate slowed, and eating disorder literature is now published at a slightly lower rate than general medical literature. Perhaps during the period of intense academic interest, clinicians were more attuned to eating disorder diagnoses and symptoms. This would have specific implications for bulimia nervosa as it is typically a hidden illness, whereas anorexia nervosa is more instantly recognisable.

Intense UK press coverage of bulimia during the 1990s might also have contributed to the apparent rise in incidence. For example, the first reports of Princess Diana's battle with bulimia appeared in Andrew Morton's 1992 book Diana: Her True Story (Morton, 1992), and subsequent media interest might have focused attention on bulimic symptoms and improved public awareness of the disorder. It is notable that the Princess's death in 1997 coincided with the beginning of the decline in bulimia incidence. Greater familiarity has been implicated in the increased incidence of other diseases, including autism and repetitive strain injury (Brogmus et al, 1996; Kaye et al, 2001). Identification with a public figure's struggle with bulimia might have temporarily decreased the shame associated with the illness, and encouraged women to seek help for the first time. This would suggest that some of the 1990s peak might have been caused by the identification of long-standing cases, rather than a true increase in community incidence. The finding that the recent decline is largely due to a reduction in incidence in the older group (women aged 20-39 years) supports this conclusion.

\section{FUTURE WORK}

Further research is needed to determine whether the reported incidence of bulimia nervosa will continue to decline in the $\mathrm{UK}$, or whether this is the beginning of a stabilisation that echoes the stable incidence observed for anorexia nervosa. This work suggests a need for increased recognition and treatment efforts, especially for adolescent women. Even subclinically disordered eating behaviour during adolescence elevates the risk of a broad range of physical and mental health problems during early adulthood (Johnson et al, 2002) and eating disorder symptoms in adolescence confer a strong risk of eating disorders in young adulthood (Kotler et al, 2001). In addition, the National Institute for Clinical Excellence (2004) has recently called attention to the lack of research in adolescents with bulimia nervosa. Given that this age group now shows the highest incidence of bulimia in primary care, there needs to be renewed emphasis on research in this area.

\section{REFERENCES}

American Psychiatric Association (1994) Diagnostic and Statistical Manual of Mental Disorders (4th edn) (DSM-IV). Washington, DC: APA.

Brogmus, G. E., Sorock, G. S. \& Webster, B. S. (1996) Recent trends in work-related cumulative trauma disorders of the upper extremities in the United States: an evaluation of possible reasons. Journal of Occupational and Environmental Medicine, 38, 40I-4II.

Fairburn. C. G. \& Harrison, P. J. (2003) Eating disorders. Lancet, 36I, 407-4I6.

Hoek, H.W., Bartelds, A. I., Bosveld, J. J., et al (1995) Impact of urbanization on detection rates of eating disorders. American Journal of Psychiatry, 152, 1272-1278.

Hoek, H.W. \& van Hoeken, D. (2003) Review of the prevalence and incidence of eating disorders. International Journal of Eating Disorders, 34, 383-396.

Jick, S. S., Kaye, J. A., Vasilakis-Scaramozza, C., et al (2003) Validity of the general practice research database. Pharmacotherapy, 23, 686-689.
Johnson, J. G., Cohen, P., Kasen, S., et al (2002) Eating disorders during adolescence and the risk for physical and mental disorders during adulthood. Archives of General Psychiatry, 59, 545-552.

Kaye, J. A., del Mar Melero-Montes, M. \& Jick, H. (200I) Mumps, measles, and rubella vaccine and the incidence of autism recorded by general practitioners: a time trend analysis. BMJ, 322, 460-463.

Keel, P. K. \& Klump, K. L. (2003) Are eating disorders culture-bound syndromes? Implications for conceptualizing their etiology. Psychological Bulletin, 129, 747-769.

Kotler, L. A., Cohen, P., Davies, M., et al (200I) Longitudinal relationships betwen childhood, adolescent, and adult eating disorders. Journal of the American Academy of Child and Adolescent Psychiatry, 40, 1434-1440.

Lewinsohn, P., Striegel-Moore, R. H. \& Seeley, J. R. (2000) Epidemiology and natural course of eating disorders in young women from adolescence to young adulthood. Journal of the American Academy of Child and Adolescent Psychiatry, 39, 1284-1292.

Lucas, A. R., Crowson, C. S., O'Fallon, W. M., et al (1999) The ups and downs of anorexia nervosa. International journal of Eating Disorders, 26, 397-405.

Millar, H. R. (1998) New eating disorder service. Psychiatric Bulletin, 22, 75I-754.

Morton, A. (1992) Diana: Her True Story. London: Pocket.

National Institute for Clinical Excellence (2004) Eating Disorders: Core Interventions in the Treatment and Management of Anorexia Nervosa, Bulimia Nervosa and Related Eating Disorders. CG9. London: NICE.

Ricca, V., Mannucci, E., Mezzani, B., et al (200I) Psychopathological and clinical features of outpatients with an eating disorder not otherwise specified. Eating and Weight Disorders, 6, 157-165.

Soundy, T., Lucas, A. R., Suman, V., et al (1995) Bulimia nervosa in Rochester, Minnesota from 1980 to 1990. Psychological Medicine, 25, 1065-1071.

Theander, S. S. (2002) Literature on eating disorders during 40 years: increasing number of papers, emergence of bulimia nervosa. European Eating Disorders Review, 10, 386-398.

Turnbull, S., Ward, A., Treasure, J., et al (1996) The demand for eating disorder care. An epidemiological study using the general practice research database. British Journal of Psychiatry, 169, 705-712.

Turner, H. \& Bryant-Waugh, R. (2004) Eating disorder not otherwise specified (EDNOS) profiles of clients presenting at a community eating disorder service. European Eating Disorder Review, 12, 18-26.

Walley, T. \& Mantgani, A. (1997) The UK General Practice Research Database. Lancet, 350, 1097-1099. 